\title{
Similar outcomes with first-line observation versus metastasectomy for bone giant cell tumor lung metastases
}

\author{
Shinji Tsukamoto ( $\nabla$ shinji104@mail.goo.ne.jp ) \\ https://orcid.org/0000-0002-8419-2008 \\ Giovanni Ciani \\ IRCCS Istituto Ortopedico Rizzoli \\ Andreas F. Mavrogenis \\ National and Kapodistrian University of Athens \\ Cristina Ferrari \\ IRCCS Istituto Ortopedico Rizzoli \\ Manabu Akahane \\ National Institute of Public Health \\ Yasuhito Tanaka \\ Nara Medical University \\ Michele Rocca \\ IRCCS Istituto Ortopedico Rizzoli \\ Alessandra Longhi \\ IRCCS Istituto Ortopedico Rizzoli \\ Davide Maria Donati \\ IRCCS Istituto Ortopedico Rizzoli \\ Costantino Errani \\ IRCCS Istituto Ortopedico Rizzoli
}

\section{Research article}

Keywords: Giant cell tumor of bone, Observation, Metastasectomy, Denosumab, Metastasis, Lungs

Posted Date: June 8th, 2020

DOI: https://doi.org/10.21203/rs.3.rs-30256/v1

License: (a) This work is licensed under a Creative Commons Attribution 4.0 International License.

Read Full License 


\section{Abstract}

Background: The outcome of lung metastases in patients with giant cell tumor of bone (GCTB) varies from spontaneous regression to uncontrolled growth. To investigate whether observation is an appropriate first-line management for patients with lung metastases from GCTB, we compared the outcomes of patients initially treated with observation with those treated with metastasectomy.

Methods: We retrospectively reviewed the data of 29 patients with lung metastases from histologically confirmed GCTB. The median follow-up period was 114 months. We evaluated progression-free survival, which was defined as the time from the date of occurrence of lung metastases to the date of disease progression in the observation or incomplete metastasectomy group, disease recurrence in the complete metastasectomy group, or the last follow-up.

Results: Disease progression or recurrence occurred in 14 patients (48.3\%). Progression-free survival did not vary significantly between the observation and metastasectomy groups ( $p=0.373)$. The number of metastasectomies was significantly higher in the initial metastasectomy group than in the observation group $(p=0.017)$.

Conclusions: Observation can be used safely as first-line management for patients with lung metastases from GCTB with an outcome similar to that of metastasectomy.

\section{Background}

Giant cell tumor of bone (GCTB) accounts for approximately $5 \%$ of all primary bone tumors [1]. It usually involves the metaphyseal-epiphyseal region of long bones [2] and its incidence peaks in the third and fourth decade [3]. The main treatment modality is surgery, consisting of curettage or en block resection.

Although benign, GCTB is known to be locally aggressive with a tendency for local recurrence with occasional metastatic potential [4]. GCTBs metastasize in up to $4 \%$ of cases, mainly to lung [5-16]. Treatment recommendations of lung metastasis vary; the most common is metastasectomy [8,17-22], but chemotherapy (cytotoxic agents [21,23], denosumab [24-26], interferon- a [27], or bisphosphonates [28]), radiation [17,29,30], and observation [20] have each been reported with varying effectiveness. Some patients with lung metastasis have been reported to experience uncontrolled growth, eventually resulting in death [31]. Other patients with lung metastases can spontaneously regress or present growth arrest [31]; therefore, these patients would benefit from a wait-and-see policy without the use of surgical or medical treatments. Before 2010, many authors recommended, when feasible, an immediate metastasectomy $[11,16,32-35]$. Recently, some authors have proposed that metastasectomy should only be recommended when accompanied by disease progression or developing a symptom [12,36-38]. The aim of the wait-and-see policy was to determine with observation the biologic behavior of lung metastases and determine further treatment, based on disease progression. However, there is limited information regarding the ideal treatment approach of patients with metastatic GCTB. 
Therefore, to confirm whether observation is appropriate as a first-line approach for patients with lung metastases from GCTB, we performed a retrospective study to compare the outcomes between patients initially treated with observation and those treated with metastasectomy.

\section{Methods}

We retrospectively reviewed the medical records of 496 patients diagnosed with histologically confirmed GCTB in a single institution between 1984 and 2019. Of the 496 patients, 32 experienced lung metastases as evident by computed tomography (CT) of the chest. Three of the 32 patients were excluded due to malignant transformation of GCTB. The remaining 29 patients were included in this study for further analysis. We evaluated the primary tumor characteristics as shown in Table 1. Tumors were graded radiographically according to the Campanacci classification system for GCTB [9]. Primary tumor surgeries were performed with curettage or resection. The tumor cavity after curettage was left alone or packed with bone allografts, cement, or cement with bone allografts, as reported in previous study [39-41]. Resection was indicated for large tumors with soft tissue extension, pathological fractures with joint invasion or an unstable fracture pattern, multiple recurrences, or involvement of expendable bones (head of the fibula or distal end of the ulna), as previously reported [39].

After primary tumor treatment, the patients were followed every four months for the first 2 years, every 6 months for the next 3 years, and then annually. Follow-up evaluation included radiographs of the primary tumor area and CT of the chest. We evaluated the lung metastases characteristics including number of lung nodules, size of maximum nodule, solitary or multiple lesion, and laterality (unilateral or bilateral) as shown in Table 1. Seven of the 29 patients had lung metastases at presentation and the remaining patients had metachronous metastases. The median interval between surgery of primary tumor and occurrence of lung metastasis was 22 months (interquartile range [IQR], 5 to 37.5 months). Twenty-three patients underwent observation as the first-line approach. Eight of them received metastasectomy and 2 of them received denosumab treatment $(120 \mathrm{mg})$ for 1 year and 11 years, respectively, due to progression of lung metastases. One of the 2 patients received chemotherapy (ifosfamide, adriamycin, interferon, or cyclophosphamide) before starting denosumab treatment. The median interval between occurrence of lung metastasis and metastasectomy was 14 months (IQR, 6 to 15 months). Six patients received metastasectomy as the first line approach. One patient received stereotactic radiotherapy due to a recurrent tumor following metastasectomy (Figure 1).

Lung lesion size was assessed by CT as complete response, partial response, stable disease, or progressive disease, as measured by the modified Response Evaluation Criteria in Solid Tumors (RECIST; version 1.1) that assess tumor extent on the basis of the sum of the longest diameter of a lesion [42]. The Fisher's exact test was used to compare 2 variables. The difference between 2 independent samples was statistically analyzed using the Mann-Whitney $U$ test for nonparametric analyses. Progression free survival was defined as the time from the date of occurrence of lung metastases to the date of lung lesion progression in observation or incomplete metastasectomy group, lung lesion recurrence in complete metastasectomy group, or the last follow-up. Progression-free survival was evaluated with the 
Kaplan-Meier survival analysis; survival curves were compared with a log-rank test. Analyses were performed with JMPß 14 (SAS Institute Inc., Cary, NC, USA).

\section{Results}

Progression-free survival was not significantly different between the observation and metastasectomy groups ( $p=0.373$; Figure 2) (Table 2). There were no significant differences between any variables in progression-free survival (Table 2). There was no significant difference between the observation and metastasectomy groups in patient characteristics (Table 1). Patient outcomes are summarized in Figure 1. Two patients received denosumab treatment due to disease progression. In 1 of the two patients, CT showed disease progression one year after occurrence of lung metastases and the patient was treated with chemotherapy (ifosfamide, adriamycin, and interferon). CT showed continued disease progression 4 months after chemotherapy commencement and so the patient underwent cyclophosphamide; however, the lung lesions progressed. Denosumab was started 4 years after occurrence of lung metastases and continued for 11 years and the disease remained stable. In the other patient, chest CT showed lung lesion progression 3 years after the curettage for the primary tumor and the patient was treated with denosumab for 1 year and was observed with stable disease until last follow up. The denosumab therapy was rechallenge because the patient had denosumab treatment before and after curettage of the primary tumor. The patient had no side effects related to the denosumab treatment (Figure 3 ). In the observation group (23 patients), 15 patients did not undergo metastasectomy (65.2\%), 4 patients underwent metastasectomy once (17.4\%), and 3 patients had several metastasectomies (13.0\%). The number of metastasectomies in patients treated with initial metastasectomy was 1 in 5 patients (83.3\%) and 2 in 1 patient $(16.7 \%)$. Thus, the number of metastasectomies was significantly higher in the initial metastasectomy group than in the observation group $(p=0.017)$.

Overall, disease progression or recurrence occurred in 14 patients (48.3\%). The median follow-up period from surgery for primary tumor was 113.9 months (IQR, 80.9 to 140.6 months). The median follow-up period from occurrence of lung metastases was 72 months (IQR, 48 to 124 months). With respect to the oncologic results, 12 had no evidence of disease and 17 patients were alive with lung metastases. None of the patients died due to the disease. None of the patients had pleural effusion or respiratory symptoms. None of the patients experienced metastases anywhere but the lungs. All patients with metastasectomy had histological confirmation of their GCTB lung metastases.

\section{Discussion}

The results of our study revealed similar progression-free survival with the observation approach when compared to metastasectomy as a first-line approach in patients with metastatic GCTB. Before 2010, many authors stressed the importance of early detection of metastasis in GCTB with regular long-term follow up and recommended, where possible, appropriate immediate surgical resection, such as metastasectomy, wedge resection, or lobectomy, to prevent progressive pulmonary dysfunction $[11,16,32-35]$. On the other hand, a few authors suggested that pulmonary metastases has a good long- 
term prognosis and should be kept under observation, avoiding aggressive treatment such as lobectomy, chemotherapy, and radiotherapy $[20,43]$. Since 2015 , authors have suggested that it is unnecessary to perform lung metastasectomy immediately after the diagnosis of metastasis and it is more appropriate to perform metastasectomy only when there is disease progression in terms of volume and number of lung metastases [12,36-38]. According to a recent systematic review regarding prognosis of metastatic GCTB, spontaneous regressions were observed in $4.5 \%$ of patients [44]. Lung metastasis of GCTB often exhibits no changes in volume [36]. Because it is impossible to predict the behavior of lung metastases from GCTB [38], it is reasonable to evaluate the tumor biology with observation in each case in order to determine further treatments such as metastasectomy or medical treatment.

The mortality of the patients who had metastases from GCTB and received metastasectomy ranged between $0 \%$ and $50 \%[2,12-14,20,31,32,34,37,45-50]$. The recurrence rate of the patients who had metastases from GCTB and received metastasectomy ranged between $0 \%$ and $50 \%$ $[2,13,14,20,31,32,37,45,46,49]$. The outcome following metastasectomy varied due to unpredictable tumor behavior of lung metastases from GCTB. Literature showed that aggressive lung metastasectomy might fail to produce a cure [51].

Although the efficacy of cytotoxic chemotherapy for lung metastases from GCTB has been scarcely reported [34,52], its role is loosely determined. Thus, considering that GCTBs are borderline tumors, they are not responsive to chemotherapy even after the appearance of the lung metastases [48].

There is anecdotal evidence that interferon a-2a can be effective in stabilizing progressive GCTB refractory to other modalities such as surgery, radiation and cytotoxic chemotherapy [53-55]. Interferon may have activity in GCTB via its antiangiogenic properties. Interferon is not well-tolerated and is associated with numerous side effects, including depression and ischemic events [56].

Feigenberg et al. [57] reported 3 patients with lung metastases from GCTB who were treated with wholelung radiotherapy. One patient's lung metastasis progressed after treatment, and the patient soon died. The 2 other patients were long-term survivors ( 7.5 years and 13 years) with complete resolution of detectable disease. However, radiotherapy may induce (secondary) malignant transformation, which is of concern especially because most patients are usually relatively young. The reported risk of malignant transformation varies between $0 \%$ and $5 \%$ [58-62].

Denosumab was able to stop the progression of lung metastases in 2 patients. In 1 of the 2 patients, lung metastases progressed despite chemotherapy but denosumab halted the progression of lung metastases. Palmerini et al. [26] reported a series of 15 patients with metastatic GCTB treated with denosumab and all patients achieved tumor control under denosumab treatment. Engellau et al. [63] reported that 38 patients with metastatic GCTB, who had tumor control under denosumab treatment. Thus, denosumab could halt the disease progression in most metastatic GCTBs. In our study, 2 patients underwent denosumab treatment and achieved tumor control of lung metastases without side effects. One of these 2 patients was treated with denosumab twice before surgical treatment of the primary lesion 
and then for the treatment of lung nodules. To date, there has been no evidence that denosumab rechallenge could be effective.

Balke et al. [28] reported a series of 12 patients with metastatic GCTB who had a stable disease following bisphosphonate treatment. Li et al. [64] conducted a randomized study comparing the efficacy and safety of denosumab and zoledronic acid treatment in patients with surgically unsalvageable GCTB, including GCTB of the sacrum and spine, and multifocal tumor including lung metastases. In their study, 29 of 125 patients who were administered denosumab had lung metastasis, compared to 25 of 125 patients who were administered zoledronic acid. Zoledronic acid halted the progression of lung metastases as well as denosumab, with relatively manageable adverse effects [64].

This study has some limitations. Firstly, a power analysis was not performed, and there was a risk of type Qerror due to the small sample size. If an adequate number of patients is gathered in the future, significant differences may appear regarding the variables in this study. However, lung metastases from GCTBs are very rare. Secondly, the study was retrospective and thus had inherent limitations and risk of selection bias. Multivariable analysis was impossible due to the small sample and we were not able to correct of the influence of confounding factors. Future randomized controlled trials are needed to confirm the similar outcome between the patients initially treated with observation and those treated with metastasectomy at presentation. As no randomized trials have been performed yet, well-designed cohort and observational studies with strong effects may provide reliable information. Thirdly, we have a histological documentation for the lung nodules only for the patients who underwent resection of their lung metastases. However, most patients with GCTB are young patients and it is not frequent among healthy young patients to have newly formed lung lesions; therefore, these lung lesions when observed in imaging studies of GCTB patients most likely represent GCTB lung metastases.

\section{Conclusions}

Observation can be safely used as first-line management for patients with lung metastases from GCTB with an outcome similar to that of metastasectomy. In these patients, the goal of observation is to evaluate the tumor biology in each case to determine further treatment such as metastasectomy or medical treatment.

\section{Abbreviations}

GCTB, giant cell tumor of bone; CT, computed tomography; IQR, interquartile range; RECIST, Response Evaluation Criteria in Solid Tumors

\section{Declarations}

\section{Ethics approval and consent to participate}


All patients gave written informed consent for their data to be included in any possible future scientific study. This study was approved by the Institutional Review Board/Ethics Committee of the senior author's institution (ClinicalTrials.gov Identifier: NCT02996734).

\section{Consent for publication}

All patients gave written informed consent for their data to be included in any possible future scientific study.

\section{Availability of data and materials}

The datasets generated and/or analysed during the current study are not publicly available due to privacy problem but are available from the corresponding author on reasonable request.

\section{Competing interests}

The authors declare that they have no competing interests.

\section{Funding}

None

\section{Authors' contributions}

ST designed this study, analyzed the data and wrote this manuscript. CG gathered the data. MA performed statistical analyses. AFM, CF, YT, MR, AL, DMD integrated this study. CE designed this study and revised this manuscript. All authors read and approved the final manuscript.

\section{Acknowledgements}

The authors thank all of their patients and their families.

\section{References}

1. Fletcher CDM, Bridge JA, Hogendoorn P, Mertens F. WHO classification of tumours of soft tissue and bone. Lyon: IARC; 2013. p. 321-324.

2. Deheshi BM, Jaffer SN, Griffin AM, Ferguson PC, Bell RS, Wunder JS. Joint salvage for pathologic fracture of giant cell tumor of the lower extremity. Clin Orthop Relat Res. 2007;459:96-104.

3. Niu X, Zhang Q, Hao L, Ding Y, Li Y, Xu H, et al. Giant cell tumor of the extremity: retrospective analysis of 621 Chinese patients from one institution. J Bone Joint Surg Am. 2012;94:461-7.

4. Puri A, Gulia A, Hegde P, Verma V, Rekhi B. Neoadjuvant denosumab: its role and results in operable cases of giant cell tumour of bone. Bone Joint J. 2019;101-B:170-7. 
5. Quattrini I, Pollino S, Pazzaglia L, Conti A, Novello C, Ferrari C, et al. Prognostic role of nuclear factor/IB and bone remodeling proteins in metastatic giant cell tumor of bone: A retrospective study. J Orthop Res. 2015;33:1205-11.

6. Rock M. Curettage of giant cell tumor of bone. Factors influencing local recurrences and metastasis. Chir Organi Mov. 1990;75 1 Suppl:204-5.

7. Ghert MA, Rizzo M, Harrelson JM, Scully SP. Giant-cell tumor of the appendicular skeleton. Clin Orthop Relat Res. 2002;:201-10.

8. Bertoni F, Present D, Enneking WF. Giant-cell tumor of bone with pulmonary metastases. J Bone Joint Surg Am. 1985;67:890-900.

9. Campanacci M, Baldini N, Boriani S, Sudanese A. Giant-cell tumor of bone. J Bone Joint Surg Am. 1987;69:106-14.

10. Tubbs WS, Brown LR, Beabout JW, Rock MG, Unni KK. Benign giant-cell tumor of bone with pulmonary metastases: clinical findings and radiologic appearance of metastases in 13 cases. AJR Am J Roentgenol. 1992;158:331-4.

11. Viswanathan S, Jambhekar NA. Metastatic giant cell tumor of bone: are there associated factors and best treatment modalities? Clin Orthop Relat Res. 2010;468:827-33.

12. Chan CM, Adler Z, Reith JD, Gibbs CP. Risk factors for pulmonary metastases from giant cell tumor of bone. J Bone Joint Surg Am. 2015;97:420-8.

13. Dominkus M, Ruggieri P, Bertoni F, Briccoli A, Picci P, Rocca M, et al. Histologically verified lung metastases in benign giant cell tumours-14 cases from a single institution. Int Orthop. 2006;30:499504.

14. Takeuchi A, Tsuchiya H, Niu X, Ueda T, Jeon D-G, Wang EHM, et al. The prognostic factors of recurrent GCT: a cooperative study by the Eastern Asian Musculoskeletal Oncology Group. J Orthop Sci. 2011;16:196-202.

15. Cheng JC, Johnston JO. Giant cell tumor of bone. Prognosis and treatment of pulmonary metastases. Clin Orthop Relat Res. 1997;:205-14.

16. Kay RM, Eckardt JJ, Seeger LL, Mirra JM, Hak DJ. Pulmonary metastasis of benign giant cell tumor of bone. Six histologically confirmed cases, including one of spontaneous regression. Clin Orthop Relat Res. 1994;:219-30.

17. Maloney WJ, Vaughan LM, Jones HH, Ross J, Nagel DA. Benign metastasizing giant-cell tumor of bone. Report of three cases and review of the literature. Clin Orthop Relat Res. 1989;:208-15.

18. Gresen AA, Dahlin DC, Peterson LF, Payne WS. "Benign" giant cell tumor of bone metastasizing to lung. Ann Thorac Surg. 1973;16:531-5.

19. Goldenberg RR, Campbell CJ, Bonfiglio M. Giant-cell tumor of bone. An analysis of two hundred and eighteen cases. J Bone Joint Surg Am. 1970;52:619-64.

20. Bertoni F, Present D, Sudanese A, Baldini N, Bacchini P, Campanacci M. Giant-cell tumor of bone with pulmonary metastases. Six case reports and a review of the literature. Clin Orthop Relat Res. 
$1988 ;: 275-85$.

21. Ladanyi M, Traganos F, Huvos AG. Benign metastasizing giant cell tumors of bone. A DNA flow cytometric study. Cancer. 1989;64:1521-6.

22. Mirra JM, Ulich T, Magidson J, Kaiser L, Eckardt J, Gold R. A case of probable benign pulmonary "metastases" or implants arising from a giant cell tumor of bone. Clin Orthop Relat Res. 1982;:24554.

23. Kutchemeshgi AD, Wright JR, Humphrey RL. Pulmonary metastases from a well-differentiated giant cell tumor of bone. Report of a patient with apparent response to cyclophosphamide therapy. Johns Hopkins Med J. 1974;134:237-45.

24. Ueda T, Morioka H, Nishida Y, Kakunaga S, Tsuchiya H, Matsumoto $Y$, et al. Objective tumor response to denosumab in patients with giant cell tumor of bone: a multicenter phase II trial. Ann Oncol. 2015;26:2149-54.

25. Chawla S, Henshaw R, Seeger L, Choy E, Blay J-Y, Ferrari S, et al. Safety and efficacy of denosumab for adults and skeletally mature adolescents with giant cell tumour of bone: interim analysis of an open-label, parallel-group, phase 2 study. Lancet Oncol. 2013;14:901-8.

26. Palmerini E, Chawla NS, Ferrari S, Sudan M, Picci P, Marchesi E, et al. Denosumab in advanced/unresectable giant-cell tumour of bone (GCTB): For how long? Eur J Cancer. 2017;76:11824.

27. Wei F, Liu X, Liu Z, Jiang L, Dang G, Ma Q, et al. Interferon alfa-2b for recurrent and metastatic giant cell tumor of the spine: report of two cases. Spine. 2010;35:E1418-1422.

28. Balke M, Campanacci L, Gebert C, Picci P, Gibbons M, Taylor R, et al. Bisphosphonate treatment of aggressive primary, recurrent and metastatic Giant Cell Tumour of Bone. BMC Cancer. 2010;10:462.

29. Vanel D, Contesso G, Rebibo G, Zafrani B, Masselot J. Benign giant-cell tumours of bone with pulmonary metastases and favourable prognosis. Report on two cases and review of the literature. Skeletal Radiol. 1983;10:221-6.

30. Stargardter FL, Cooperman LR. Giant-cell tumour of sacrum with multiple pulmonary metastases and long-term survival. Br J Radiol. 1971;44:976-9.

31. Osaka S, Toriyama M, Taira K, Sano S, Saotome K. Analysis of giant cell tumor of bone with pulmonary metastases. Clin Orthop Relat Res. 1997;:253-61.

32. Siebenrock KA, Unni KK, Rock MG. Giant-cell tumour of bone metastasising to the lungs. A long-term follow-up. J Bone Joint Surg Br. 1998;80:43-7.

33. Rock MG, Pritchard DJ, Unni KK. Metastases from histologically benign giant-cell tumor of bone. J Bone Joint Surg Am. 1984;66:269-74.

34. Faisham WI, Zulmi W, Halim AS, Biswal BM, Mutum SS, Ezane AM. Aggressive giant cell tumour of bone. Singapore Med J. 2006;47:679-83.

35. Takanami I, Takeuchi K, Naruke M, Kodaira S. Aggressive surgery for treating a pulmonary metastasis of a benign giant cell tumor of the bone: results in four cases. $J$ Thorac Cardiovasc Surg. 
$1998 ; 116: 649-51$.

36. Kito M, Matusmoto S, Ae K, Tanizawa T, Gokita T, Kobayashi H, et al. Pulmonary metastasis from giant cell tumor of bone: clinical outcome prior to the introduction of molecular target therapy. Jpn $\mathrm{J}$ Clin Oncol. 2017;47:529-34.

37. Chen C-C, Liau C-T, Chang C-H, Hsu Y-H, Shih H-N. Giant Cell Tumors of the Bone With Pulmonary Metastasis. Orthopedics. 2016;39:e68-73.

38. Rosario M, Kim H-S, Yun JY, Han I. Surveillance for lung metastasis from giant cell tumor of bone. J Surg Oncol. 2017;116:907-13.

39. Errani C, Ruggieri P, Asenzio MAN, Toscano A, Colangeli S, Rimondi E, et al. Giant cell tumor of the extremity: A review of 349 cases from a single institution. Cancer Treat Rev. 2010;36:1-7.

40. Errani C, Tsukamoto S, Leone G, Akahane M, Cevolani L, Tanzi P, et al. Higher local recurrence rates after intralesional surgery for giant cell tumor of the proximal femur compared to other sites. Eur $\mathrm{J}$ Orthop Surg Traumatol. 2017;27:813-9.

41. Tsukamoto S, Mavrogenis AF, Tanzi P, Leone G, Akahane M, Tanaka Y, et al. Curettage as first surgery for bone giant cell tumor: adequate surgery is more important than oncology training or surgical management by high volume specialized teams. Eur J Orthop Surg Traumatol. 2020;30:3-9.

42. Eisenhauer EA, Therasse P, Bogaerts J, Schwartz LH, Sargent D, Ford R, et al. New response evaluation criteria in solid tumours: revised RECIST guideline (version 1.1). Eur J Cancer. 2009;45:228-47.

43. Sanjay BK, Kadhi SM. Giant cell tumour of bone with pulmonary metastases. A report of three cases. Int Orthop. 1998;22:200-4.

44. Itkin B, Straminsky S, De Ronato G, Lewi D, Marantz A, Bardach A. Prognosis of metastatic giant cell tumor of bone in the pre-denosumab era. A systematic review and a meta-analysis. Jpn J Clin Oncol. 2018;48:640-52.

45. Donthineni R, Boriani L, Ofluoglu O, Bandiera S. Metastatic behaviour of giant cell tumour of the spine. Int Orthop. 2009;33:497-501.

46. He H, Zeng H, Luo W, Liu Y, Zhang C, Liu Q. Surgical Treatment Options for Giant Cell Tumors of Bone Around the Knee Joint: Extended Curettage or Segmental Resection? Front Oncol. 2019;9:946.

47. Kremen TJ, Bernthal NM, Eckardt MA, Eckardt JJ. Giant cell tumor of bone: are we stratifying results appropriately? Clin Orthop Relat Res. 2012;470:677-83.

48. Liu J, Yang H, Sun R, Yang Z, Zhu Z. Retrospective analysis of patients with rare-site and metastatic giant cell tumor. Chin J Cancer Res. 2013;25:585-92.

49. Tsukamoto S, Mavrogenis AF, Leone G, Righi A, Akahane M, Tanzi P, et al. Denosumab does not decrease the risk of lung metastases from bone giant cell tumour. Int Orthop. 2019;43:483-9.

50. Wang T, Chan CM, Yu F, Li Y, Niu X. Does Wrist Arthrodesis With Structural Iliac Crest Bone Graft After Wide Resection of Distal Radius Giant Cell Tumor Result in Satisfactory Function and Local Control? Clin Orthop Relat Res. 2017;475:767-75. 
51. Jacopin S, Viehweger E, Glard Y, Launay F, Jouve J-L, Bouvier C, et al. Fatal lung metastasis secondary to index finger giant cell tumor in an 8-year-old child. Orthop Traumatol Surg Res. 2010;96:310-3.

52. Stewart DJ, Belanger R, Benjamin RS. Prolonged disease-free survival following surgical debulking and high-dose cisplatin/doxorubicin in a patient with bulky metastases from giant cell tumor of bone refractory to "standard" chemotherapy. Am J Clin Oncol. 1995;18:144-8.

53. Kaban LB, Mulliken JB, Ezekowitz RA, Ebb D, Smith PS, Folkman J. Antiangiogenic therapy of a recurrent giant cell tumor of the mandible with interferon alfa-2a. Pediatrics. 1999;103 6 Pt 1:11459.

54. Dickerman JD. Interferon and giant cell tumors. Pediatrics. 1999;103 6 Pt 1:1282-3.

55. Kaiser U, Neumann K, Havemann K. Generalised giant-cell tumour of bone: successful treatment of pulmonary metastases with interferon alpha, a case report. J Cancer Res Clin Oncol. 1993;119:3013.

56. Ng VY, Davidson DJ, Kim EY, Pollack SM, Conrad lii EU, Jones RL. The multidisciplinary management of giant cell tumor of bone. Expert Rev Anticancer Ther. 2014;14:783-90.

57. Feigenberg SJ, Marcus RB, Zlotecki RA, Scarborough MT, Enneking WF. Whole-lung radiotherapy for giant cell tumors of bone with pulmonary metastases. Clin Orthop Relat Res. 2002;:202-8.

58. Shi W, Indelicato DJ, Reith J, Smith KB, Morris CG, Scarborough MT, et al. Radiotherapy in the management of giant cell tumor of bone. Am J Clin Oncol. 2013;36:505-8.

59. Ruka W, Rutkowski P, Morysiński T, Nowecki Z, Zdzienicki M, Makula D, et al. The megavoltage radiation therapy in treatment of patients with advanced or difficult giant cell tumors of bone. Int $\mathrm{J}$ Radiat Oncol Biol Phys. 2010;78:494-8.

60. Chakravarti A, Spiro IJ, Hug EB, Mankin HJ, Efird JT, Suit HD. Megavoltage radiation therapy for axial and inoperable giant-cell tumor of bone. J Bone Joint Surg Am. 1999;81:1566-73.

61. Malone S, O'Sullivan B, Catton C, Bell R, Fornasier V, Davis A. Long-term follow-up of efficacy and safety of megavoltage radiotherapy in high-risk giant cell tumors of bone. Int $\mathrm{J}$ Radiat Oncol Biol Phys. 1995;33:689-94.

62. Nair MK, Jyothirmayi R. Radiation therapy in the treatment of giant cell tumor of bone. Int J Radiat Oncol Biol Phys. 1999;43:1065-9.

63. Engellau J, Seeger L, Grimer R, Henshaw R, Gelderblom H, Choy E, et al. Assessment of denosumab treatment effects and imaging response in patients with giant cell tumor of bone. World $\mathrm{J}$ Surg Oncol. 2018;16:191.

64. Li S, Chen P, Yang Q. Denosumab versus zoledronic acid in cases of surgically unsalvageable giant cell tumor of bone: A randomized clinical trial. J Bone Oncol. 2019;15:100217.

\section{Tables}


Table 1. Details of the patients included in this study at baseline.

First-line approach

Variables

$\begin{array}{llll}\begin{array}{l}\text { Patients } \\ (\mathrm{n}=29,\end{array} & \begin{array}{l}\text { Observation } \\ (\mathrm{n}=23,\end{array} & \begin{array}{l}\text { Metastasectomy } \\ (\mathrm{n}=6,20.7 \%)\end{array} & \begin{array}{l}p \\ \text { value }\end{array} \\ \%) & 79.3 \%) & & \end{array}$

Age (years)

0.080

Median

28.2

31.3

23.4

IQR

24.4-

$26.0-36.8$

20.8-36.3

36.6

Sex

0.258

Male

Female

$9,31.0 \%$

6, $26.1 \%$

$3,50.0 \%$

20 ,

$69.0 \%$

$17,73.9 \%$

$3,50.0 \%$

Site

$0.869^{\#}$

Distal radius

$7,24.1 \%$

$5,21.7 \%$

$2,33.3 \%$

Proximal femur

$1,3.4 \% \quad 0$

$1,16.7 \%$

Distal femur

$4,13.8 \%$

$3,13.0 \%$

$1,16.7 \%$

Proximal tibia

$6,20.7 \%$

$6,26.1 \%$

0

Proximal fibula

$1,3.4 \%$

$1,4.3 \%$

0

Proximal humerus

$2,6.9 \% \quad 1,4.3 \%$

$1,16.7 \%$

Ilium

$1,3.4 \%$

$1,4.3 \%$

0

Ischium

$1,3.4 \%$

$1,4.3 \%$

0

Vertebra

$2,6.9 \% \quad 1,4.3 \%$

$1,16.7 \%$

Phalanx

$1,3.4 \% \quad 1,4.3 \%$

0

Metacarpal

$2,6.9 \%$

$2,8.7 \%$

0

Metatarsal

$1,3.4 \% \quad 1,4.3 \%$

0

Campanacci classification

Stage II

Stage III

Previous surgery

No
$6,20.7 \%$

23 ,

$79.3 \%$
$4,17.4 \%$

$19,82.6 \%$
$2,33.3 \%$

$4,66.7 \%$ 
$\begin{array}{llll}\text { Yes } & 8,27.6 \% & 8,34.8 \% & 0\end{array}$

Lung metastasis at presentation

No

22 ,

$75.9 \%$

Yes

$7,24.1 \% \quad 7,30.4 \%$

$16,69.6 \%$

$6,100.0 \%$

0

Pathological fracture at presentation

No

20 ,

$69.0 \%$

Yes

$9,31.0 \%$

$6,26.1 \%$

$3,50.0 \%$

Surgery for primary tumor

Curettage

$7,24.1 \%$

$6,26.1 \%$

$1,16.7 \%$

Resection

22 ,

$75.9 \%$

$17,73.9 \%$

$5,83.3 \%$

$3,50.0 \%$

Pre- and postoperative denosumab treatment

No

25

$86.2 \%$

$19,82.6 \%$

$6,100.0 \%$

Yes

$4,13.8 \%$

$4,17.4 \%$

0

Local recurrence

None

15

$51.7 \%$

$1 £$

14

$48.3 \%$

$13,56.5 \% \quad 2,33.3 \%$

$10,43.5 \%$

$4,66.7 \%$

Interval between surgery of primary tumor and occurrence of lung metastasis (months)

Median

IQR

Number of lung nodules

Median

IQR

Size of maximum nodule $(\mathrm{mm})$

Median
22

$5-37.5$

22

$0-40$

$11-54.8$

5

5

10

6

4-8

0.599 


\begin{tabular}{|lcccc|}
\hline IQR & $5-10$ & $5-9$ & $3-12$ & \\
\hline Lung lesion & & & & 0.144 \\
\hline Solitary & $4,14.8 \%$ & $2,9.1 \%$ & $2,40.0 \%$ & \\
\hline Multiple & 23, & $20,90.9 \%$ & $3,60.0 \%$ & \\
\hline Laterality & $85.2 \%$ & & & \\
\hline Unilateral & & & & \\
\hline Bilateral & $5,18.5 \%$ & $3,13.6 \%$ & $2,40.0 \%$ & \\
\hline \#Comparison of distal end of the radius and the others. IQR, interquartile range & \\
\hline
\end{tabular}


Table 2. Univariate analysis for progression-free survival

\section{Variable}

Age (years)

$<30$

$30 £$

Sex

Male

Female

Site

Distal radius

Other sites

Campanacci classification

Stage II

Stage III

Previous surgery

No

Yes

Lung metastasis at presentation

No

Yes

Pathological fracture at presentation

No

Yes

Surgery for primary tumor

Curettage

Resection

Pre- and postoperative denosumab treatment
No. of patients

Five-year progression-free survival $(95 \% \mathrm{Cl})(\%)$

p value 0.436

16

13

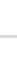

9

20

7

22

$7 \quad 42.9(14.4-77.0)$

2

$42.9(14.4-77.0)$
$59.1(38.2-77.2)$

$50.0(27.3-72.7)$

$59.3(31.4-82.3)$

$77.8(42.1-94.4)$

$42.9(22.8-65.6)$

0.896

0.108

$77.8(42.1-94.4)$
20

6

23

$50.0(16.8-83.2)$

55.8 (35.4-74.4)

0.896

$15 \quad 53.3(29.3-75.9)$

14

$55.1(29.0-78.7)$

4

22

7

59.1 (38.2-77.2)

$38.1(10.5-76.3)$

20

9

48.9 (28.0-70.1)

$66.7(33.3-88.9)$

0.620

0.264

20

9

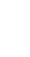

7

22

57.1 (23.0-85.6)

$54.5(34.1-73.5)$

$\begin{array}{ll}7 & 57.1(23.0-85.6) \\ 22 & 54.5(34.1-73.5)\end{array}$

0.801

\begin{tabular}{|lll}
\hline No & 25 & $60.0(40.3-77.0)$ \\
\hline Yes & 4 & $25.0(3.4-76.2)$
\end{tabular}

Page 15/19 


\begin{tabular}{|c|c|c|c|}
\hline Local recurrence & & & 0.896 \\
\hline None & 15 & $53.3(29.3-75.9)$ & \\
\hline 31 & 14 & $55.1(29.0-78.7)$ & \\
\hline $\begin{array}{l}\text { Interval between surgery of primary tumor and } \\
\text { occurrence of lung metastasis (months) }\end{array}$ & & & 0.610 \\
\hline$<24$ & 17 & $45.4(23.6-69.1)$ & \\
\hline $24 £$ & 12 & $66.7(37.6-86.9)$ & \\
\hline Number of nodules & & & 0.435 \\
\hline$<4$ & 7 & $57.1(23.0-85.6)$ & \\
\hline $4 £$ & 11 & $45.5(20.3-73.2)$ & \\
\hline Lung lesion & & & 0.302 \\
\hline Solitary & 4 & $75.0(23.8-96.6)$ & \\
\hline Multiple & 23 & $47.0(27.8-67.1)$ & \\
\hline Laterality & & & 0.625 \\
\hline Unilateral & 5 & $60.0(20.0-90.0)$ & \\
\hline Bilateral & 22 & $49.1(29.1-69.3)$ & \\
\hline Size of maximum nodule $(\mathrm{mm})$ & & & 0.060 \\
\hline$<6$ & 12 & $66.7(37.6-86.9)$ & \\
\hline $6 f$ & 7 & $14.3(2.0-58.1)$ & \\
\hline First-line approach & & & 0.373 \\
\hline Observation & 23 & $50.9(30.8-70.6)$ & \\
\hline Metastasectomy & 6 & $66.7(26.8-91.6)$ & \\
\hline
\end{tabular}

Figures 


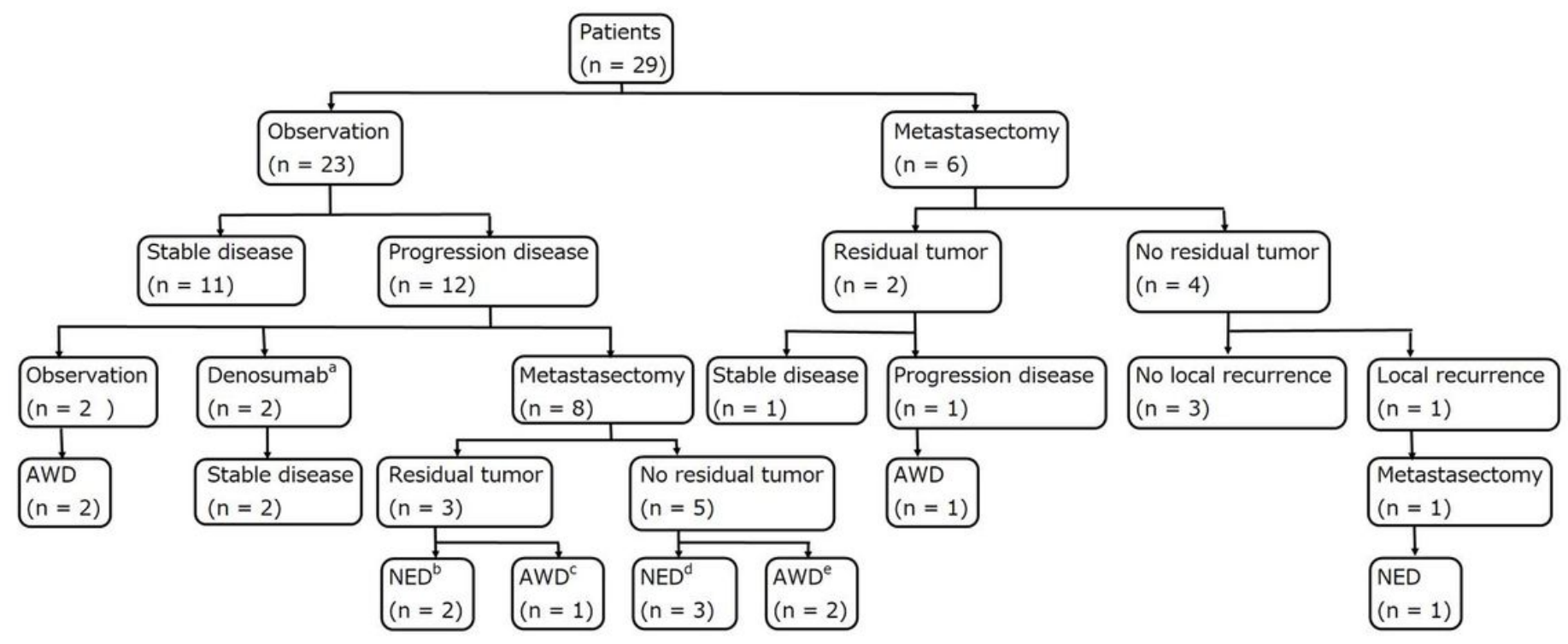

Figure 1

Diagram of patient outcomes. a, One of the two patients received chemotherapy before starting denosumab treatment. Lung lesions progressed under the chemotherapy; $b$, One patient received metastasectomy again due to slow progression and never experienced recurrence. The other patient received metastasectomy 3 more times due to slow progression and never experienced recurrence since then; $c$, The patient had lung lesion with slow progression; $d$, One of the 3 patients experienced recurrence, received stereotactic radiotherapy and the lung lesion regressed. Another patient experienced recurrence, underwent metastasectomy, and no further recurrence was observed; e, Two patients experienced recurrences. NED, no evidence of disease; AWD, alive with disease; 


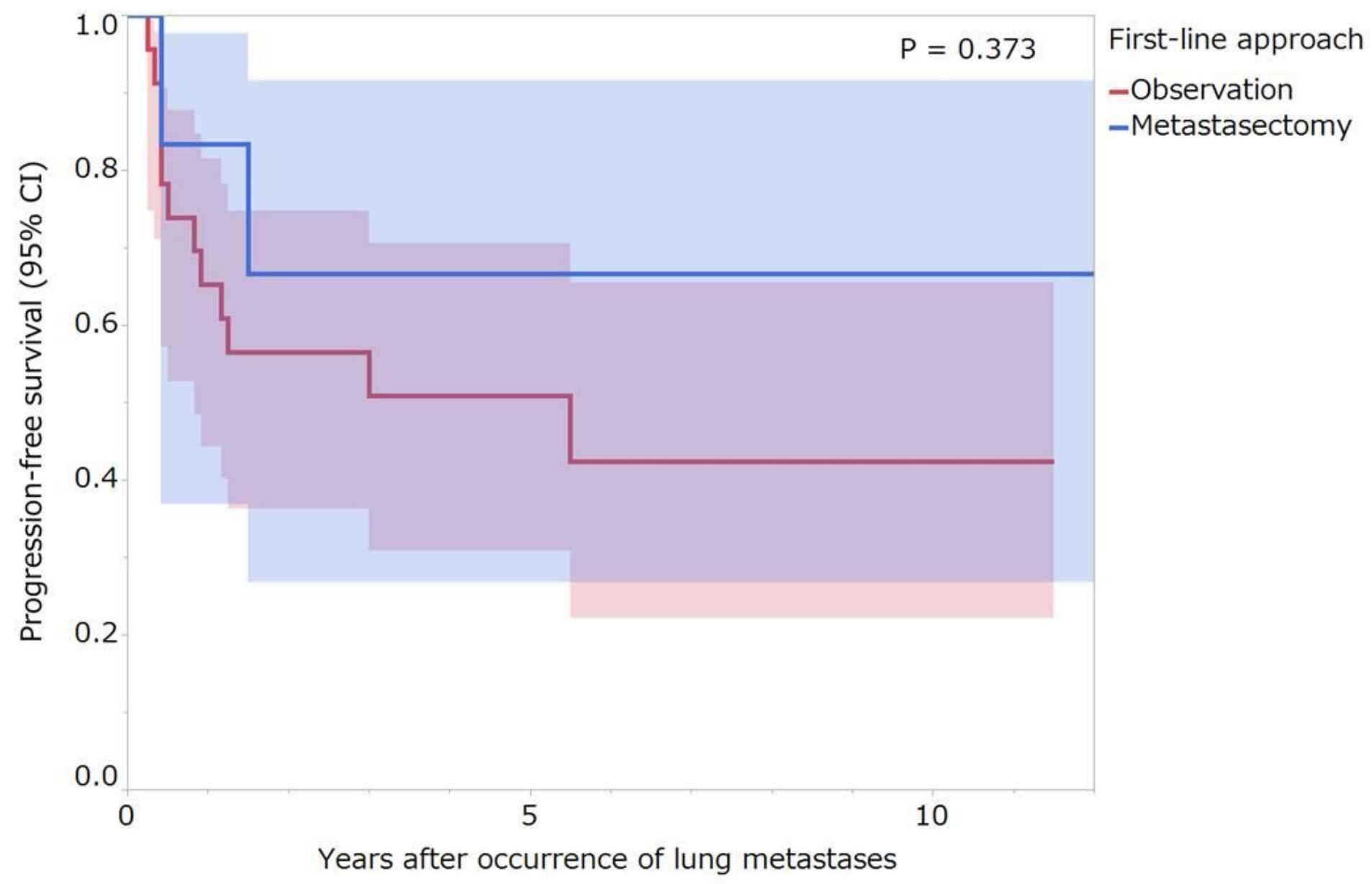

Figure 2

A Kaplan-Meier curve showing the similar progression-free survival in patients treated with observation and those treated with metastasectomy. 

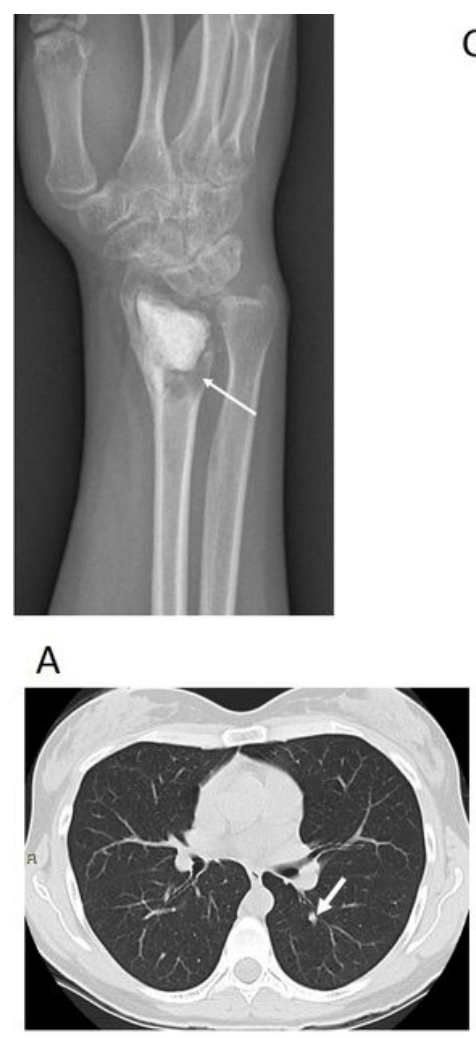

B

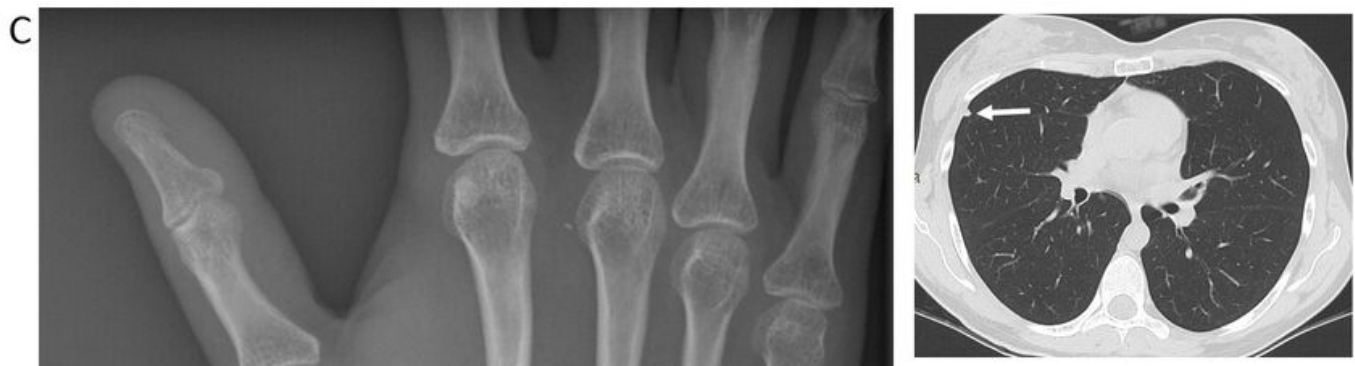

D

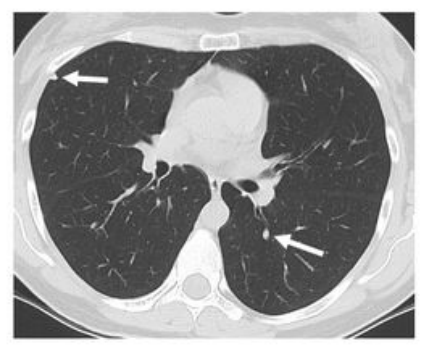

$\mathrm{E}$

\section{Figure 3}

A case of 33-year-old woman with giant cell tumor of bone and lung metastases treated with denosumab rechallenge. She was referred to our institute for the local recurrence following curettage and cementing for distal radius giant cell tumor of bone. Radiograph showed osteolytic lesions (arrow) surrounding the cement (a). Chest CT showed lung metastasis on the left lung (arrow) at presentation (b). She received preoperative denosumab therapy for 4 months and radiograph showed sclerotic formation (arrow) surrounding the cement (c). Then she received curettage and cementing and postoperative denosumab therapy for one month. However, she experienced local recurrence 14 months after the operation and received en bloc resection and reconstruction with allograft. Follow up chest CT showed a new lesion on the right lung (arrow) 3 years after the initial operation at our institute (d). She was treated with denosumab for 1 year and the lung lesions were stable (arrows) thereafter (e). 